\title{
ANALISIS ATRIBUT-ATRIBUT DAN POSISI OPERATOR GSM (GLOBAL SYSTEM FOR MOBILE COMMUNICATIONS) BERDASARKAN PREFERENSI PELANGGAN
}

\author{
BOBY CANIGIA, FERRA YANUAR, DODI DEVIANTO \\ Program Studi Matematika, \\ Fakultas Matematika dan Ilmu Pengetahuan Alam, Universitas Andalas, \\ Kampus UNAND Limau Manis Padang, Indonesia, \\ bobyvictraz@gmail.com
}

\begin{abstract}
Abstrak. Penelitian ini bertujuan mengetahui posisi persaingan operator GSM (Global System for Mobile Communications) berdasarkan preferensi konsumen di kalangan Mahasiswa Jurusan Matematika UNAND. Penelitian ini menggunakan alat analisis multivariat IPA dan MDS. Dengan menggunakan alat analisis multivariat Importance Performance Analysis (IPA) hasil penelitian yang diperoleh terlihat posisi atribut-atribut dari masing-masing operator berdasarkan kuadran perbaikannya. Dengan menggunakan Multi Deminsional Scaling (MDS) hasil penelitian yang diperoleh terdapat perbedaan posisi masing-masing operator telepon seluler prabayar berdasarkan preferensi konsumen. Pada spatial map MDS menunjukkan bahwa posisi As dan Simpati yang bernaung pada perusahaan Telkomsel berada pada posisi yang berdekatan. Artinya As dan Simpati memiliki kemiripan berdasarkan preferensi Mahasiswa Matematika UNAND. As dan Simpati tidak memiliki kemiripan terhadap XL, Axis, IM3 dan Tri yang terlihat dari posisi produk Telkomsel ini yang jauh dari operator lain. IM3, Tri dan XL memiliki kemiripan yang terlihat dari posisi ketiga GSM ini yang berdekatan. Axis berdiri sendiri pada dimensi 1 negatif dan dimensi 2 negatif. Artinya Axis tidak memiliki kemiripan terhadap operator GSM manapun.
\end{abstract}

Kata Kunci: Operator GSM, atribut, preferensi, statistik multivariat, importance performance analysis, Multidimensional Scaling

\section{Pendahuluan}

Pada zaman globalisasi ini, perkembangan teknologi maju semakin cepat. Perkembangan teknologi ini tentu tidak dapat dipisahkan dari telekomunikasi yang mendukung. Di Indonesia pertumbuhan telekomunikasi khususnya operator seluler berkembang sangat pesat. Peningkatan pelanggan telepon selular yang sangat pesat pada setiap tahunnya membuat persaingan antara perusahaan-perusahaan operator seluler di Indonesia menjadi sangat ketat. Setiap perusahaan berusaha untuk memberikan tawaran-tawaran atribut yang menarik kepada para pelanggan maupun calon pelanggannya dengan tujuan untuk mendapatkan pelanggan sebanyak-banyaknya. Atribut-atribut seperti kualitas sinyal, luasnya jaringan, tarif telepon dan SMS serta tarif paket data internet menjadi hal yang diprioritaskan oleh operator seluler disamping atribut-atribut lainnya. Dengan analisis multivariat kita dapat melakukan penelitian terhadap lebih dari dua variabel secara 
bersamaan. Contoh, menganalisis pengaruh variabel kualitas suatu produk, harga dan pendistribusian terhadap kepuasan pelanggan. Alat analisis multivariat yang digunakan adalah Importance Performance Analysis(IPA) dan Multidimensional Scaling (MDS).

\section{Matriks}

Definisi 2.1. [2] Suatu matriks adalah jajaran empat persegi panjang dari bilanganbilangan. Bilangan-bilangan dalam jajaran tersebut dinamakan entri dari matriks.

Berikut adalah contoh matriks dengan dua baris dan tiga kolom.

$$
A_{2 x 3}=\left(\begin{array}{lll}
a_{11} & a_{12} & a_{13} \\
a_{21} & a_{22} & a_{23}
\end{array}\right)
$$

Determinan dari suatu matriks A biasa ditulis $\operatorname{det}(A)$. Untuk menentukan determinan suatu matriks dapat menggunakan metode ekspansi baris dan kolom [2]. Sebagai contoh, misalkan terdapat matriks $P=\left(\begin{array}{cc}2 & 3 \\ -1 & 2\end{array}\right)$. Maka $\operatorname{det} P=$ $(2 x 2)-((-1) x 3)=1$.

Definisi 2.2. [2] Jika $A$ adalah matriks nxn maka vektor tak nol $\boldsymbol{x}$ di dalam ruang $R$ berdimensi $n$ dinamakan vektor eigen dari A. Jika Ax adalah kelipatan skalar dari $\boldsymbol{x}$, yakni $A \boldsymbol{x}=\lambda \boldsymbol{x}$, untuk suatu skalar $\lambda$, maka $\lambda$ dinamakan nilai eigen dari $A$ dan $\boldsymbol{x}$ dikatakan sebuah vektor eigen yang bersesuaian dengan $\lambda$.

Untuk mencari nilai eigen dari sebuah matriks $A$ yang berukuran $n x n$, dituliskan kembali $A \mathbf{x}=\lambda \mathbf{x}$ sebagai $A \mathbf{x}=I \lambda \mathbf{x}$.

$$
A-\lambda I=0 .
$$

Jika $\mathbf{x}$ adalah vektor yang bukan vektor nol sedemikian sehingga

$$
A \mathbf{x}=\lambda \mathbf{x}
$$

maka $\mathbf{x}$ disebut vektor eigen dari matriks $A$ yang bersesuaian dengan nilai eigen $\lambda$.

\section{Norma dan Jarak Pada Ruang Berdimensi n Euclidian}

Norma Euclidian (Euclidian norm) atau panjang vektor dari suatu vektor $\mathbf{u}=$ $\left(u_{1}, u_{2}, u_{3}, \cdots, u_{n}\right)$ pada ruang berdimensi $n$ adalah

$$
|\mathbf{u}|=(u \cdot u)^{1 / 2}=\sqrt{u_{1}^{2}+u_{2}^{2}+u_{3}^{2}+\cdots+u_{n}^{2}} .
$$

Dengan cara yang serupa, jarak euclidis antara $\mathbf{u}=\left(u_{1}, u_{2}, u_{3}, \cdots, u_{n}\right)$ dan $\mathbf{v}=$ $\left(v_{1}, v_{2}, v_{3}, \cdots, v_{n}\right)$ pada ruang berdimensi n didefinisikan oleh

$$
|\mathbf{u}-\mathbf{v}|=\sqrt{\left(u_{1}-v_{1}\right)^{2}+\left(u_{2}-v_{2}\right)^{2}+\left(u_{3}-v_{3}\right)^{2}+\cdots+\left(u_{n}-v_{n}\right)^{2}} .
$$


80 Boby Canigia dkk.

\section{Importance Performance Analysis (IPA)}

Analisis ini mengaitkan antara tingkat kepentingan (importance) suatu atribut yang dimiliki oleh objek tertentu dengan kenyataan atau kinerja (performance) yang dirasakan oleh pengguna. Langkah pertama untuk analisis IPA adalah menghitung rata-rata tingkat kepentingan dan tingkat kinerja untuk setiap atribut dengan rumus:

$$
\begin{aligned}
& \bar{x}_{k}=\frac{\sum X_{i}}{n}, \\
& \bar{y}_{k}=\frac{\sum Y_{i}}{n} .
\end{aligned}
$$

dengan

$$
\begin{aligned}
\bar{x}_{k} & =\text { bobot rata-rata tingkat kinerja atribut ke }-k, \\
\bar{y}_{k} & =\text { bobot rata-rata tingkat kepentingan atribut ke }-k, \\
n & =\text { jumlah responden/sampel. }
\end{aligned}
$$

Langkah selanjutnya adalah menghitung rata-rata tingkat kepentingan dan tingkat kinerja untuk keseluruhan atribut dengan rumus:

$$
\begin{aligned}
& \overline{\bar{x}}=\frac{\sum \bar{X}_{k}}{n}, \\
& \overline{\bar{y}}=\frac{\sum \bar{Y}_{k}}{n} .
\end{aligned}
$$

Nilai $\overline{\bar{x}}$ akan memotong diagram secara tegak lurus pada sumbu vertikal, yakni sumbu yang mencerminkan kinerja atribut $(x)$ sedangkan nilai $\overline{\bar{y}}$ memotong diagram secara tegak lurus pada sumbu horizontal, yakni sumbu yang mencerminkan kepentingan atribut $(y)$. Setelah diperoleh bobot kinerja dan kepentingan atribut serta nilai rata-rata kinerja dan rata-rata kepentingan atribut, kemudian nilai-nilai tersebut diplotkan ke dalam diagram kartesius seperti yang ditunjukkan pada Gambar 1:

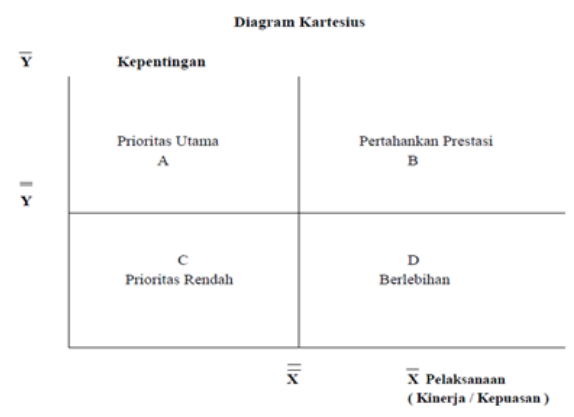

Gambar 1. Pembagian Kuadran IPA 


\section{Multidimensional Scaling}

Analisis Multidimensional Scaling merupakan salah satu teknik multivariat yang digunakan untuk mempresentasikan suatu proximites (kedekatan) antar objek dalam bentuk map (peta).

Tujuan dari Multidimensional Scaling adalah untuk mencari kordinat titik-titik dalam ruang Euclidian dari matriks jarak yang tersedia. Langkah-langkah dalam menentukan koordinat objek dalam metode MDS adalah sebagai berikut:

(1) Hitung matriks $D$

Matriks $D$ adalah matriks jarak antar objek yang menjadi penelitian. Entri dari matriks $D$ adalah $d_{i j}$ dimana $d_{i j}$ merupakan jarak euclidis antar objek yang menjadi penelitian yang dihitung dengan menggunakan rumus berdasarkan persamaan (3.1).

(2) Hitung matriks $B$

Entri-entri matriks $B$ adalah:

$$
b_{i j}=-1 / 2\left(d_{i j}^{2}-d_{i}^{2}-d_{j}^{2}+d^{2}\right)
$$

dengan $d_{i}^{2}=\frac{1}{n} \sum_{j} d_{i j}^{2} ; d_{j}^{2}=\frac{1}{n} \sum_{i} d_{i j}^{2} ; d^{2}=\frac{1}{n} \sum_{i j} d_{i j}^{2}$

(3) Dengan menggunakan persamaan (2.1) dan (2.2) selanjutnya akan dicari eigen value dan eigen vector dari matriks $B$. Eigen vector akan dinormalisasi sedemikian rupa sehingga $\gamma_{i} \gamma_{i}^{T}=1$.

Dengan memisalkan $k$ sebagai vektor eigen yang dinormalisasi, maka normalisasi eigen vektor menggunakan cara sebagai berikut:

$$
\left(k x_{1}, k x_{2}, \cdots, k x_{n}\right)\left(\begin{array}{c}
k x_{1} \\
k x_{2} \\
\ldots \\
k x_{n}
\end{array}\right)=1 \text {, jadi } k=\frac{1}{\sqrt{x_{1}^{2}+x_{2}^{2}+\ldots+x_{n}^{2}}}\left(\begin{array}{c}
x_{1} \\
x_{2} \\
\ldots \\
x_{n}
\end{array}\right)
$$

(4) Pilih jumlah dimensi

Pilih jumlah dimensi dengan menggunakan scree plot. Pada umumnya batas jumlah dimensi yang akan digunakan ditandai dengan slope yang curam antara dimensi yang satu dengan dimensi yang lainnya.

(5) Matriks $X$ yang merupakan koordinat dari titik-titik diberikan oleh $X=\Gamma \Lambda^{1 / 2}$ dimana $\Gamma$ adalah vektor yang telah dinormalisasi dan $\Lambda$ matriks diagonal dari eigen value $B$.

(6) Hitung disparities $(\hat{D})$ yang merupakan jarak euklid dari koordinat yang terbentuk pada peta.

(7) Hitung nilai stress

Nilai Stress adalah ukuran ketidakcocokkan (a lack of fit measure) yang menunjukkan ukuran ketidaktepatan suatu model MDS. Semakin kecil nilai stress yang didapatkan, semakin baik model MDS yang diperoleh. Nilai Stress diperoleh dengan menggunakan rumus [1]:

$$
\text { STRESS }=\left(\frac{\sum_{i, j=1}^{n}\left(d_{i j}-\bar{d}_{i j}^{2}\right)^{2}}{\sum_{i, j=1}^{n}\left(d_{i j}-\bar{d}\right)^{2}}\right)^{1 / 2}
$$


Boby Canigia dkk.

Kriteria kesesuaian nilai stress dicantumkan pada tabel berikut:

\begin{tabular}{|c|c|c|}
\hline No & Stress & Kesesuaian \\
\hline 1 & 20 & Buruk \\
2 & 10 & Cukup Bagus \\
3 & 5 & Bagus \\
4 & 2.5 & Sangat Bagus \\
5 & 0 & Sempurna \\
\hline
\end{tabular}

(8) Langkah 1-7 dilakukan kembali sampai $S_{i}-S_{i+1}<0,001$ terpenuhi dengan disparities $\bar{D}$ sebagai data jarak untuk $S_{2}, S_{3}, S_{4}, \cdots, S_{i+1}$

(9) Titik koordinat akhir diperoleh jika langkah 8 sudah terpenuhi.

\section{Pembahasan}

Berikut hasil penelitian dan analisa peneliti:

\subsection{IPA}

Pada bagian ini peneliti menganalisa semua operator GSM yang diteliti, yaitu operator Telkomsel, XL Axiata, Indosat, dan Three. Pada diagram kartesius IPA akan terdapat titik-titik yang akan dianalisa posisinya. Titik-titik akan diberi nomor, dimana setiap nomor tersebut mewakili atribut yang menjadi penyataan. Berikut penomoran untuk setiap atribut:

(1) Atribut Kekuatan Sinyal

(2) Atribut Luas area jaringan

(3) Atribut Kejernihan suara

(4) Atribut Tarif SMS/MMS

(5) Atribut Tarif telepon

(6) Atribut Harga kartu perdana

(7) Atribut Harga voucher isi ulang

(8) Atribut Kemudahan isi ulang pulsa

(9) Atribut Bebas roaming

(10) Aribut Masa Aktif dan Masa tenggang

(11) Atribut Bonus

(12) Atribut Pemberian Hadiah(reward)

(13) Atribut Respon pengaduan pelanggan

(14) Atribut Fasilitas operator

(15) Atribut Data paket internet

(1) Telkomsel (Simpati, As, Kartu Halo)

Berdasarkan gambar 2 dapat dilihat bahwa Tarif telepon, Harga data paket internet termasuk ke dalam kuadran I dan harus diperhatikan lagi dalam pengembangannya. Luas area jaringan, kekuatan sinyal dan kejernihan suara 


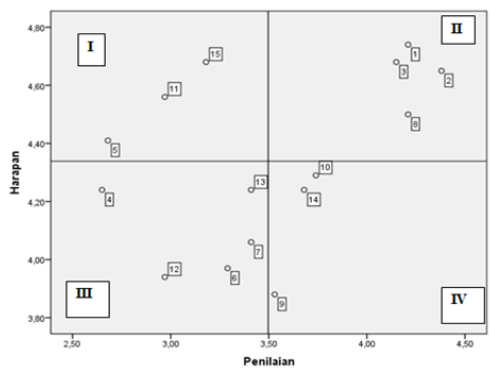

Gambar 2. Diagram Kartesius IPA Atribut-atribut Operator Telkomsel

patut dipertahankan kinerjanya karena sangat penting dan sudah dinilai baik oleh pelanggan.

(2) Indosat

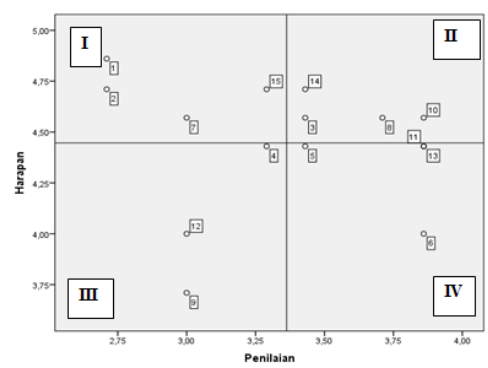

Gambar 3. Diagram Kartesius IPA Atribut-atribut Operator Indosat

Atribut-atribut yang termasuk ke kuadran prioritas utama dalam perbaikannya karna dianggap penting oleh responden, namun tidak terlaksana dengan baik oleh operator Perusahaan PT Indosat adalah, Kekuatan sinyal, Luas area jaringan, Harga voucher isi ulang pulsa, Harga data paket internet. Kejernihan suara, kemudahan isi ulang dan Masa aktif dan masa tenggang dinilai pelanggan sudah memuaskan.

(3) XL Axiata (Axis, XL)

Kekuatan sinyal, luas area jaringan dan tarif telepon masih harus menjadi tujuan utama operator XL Axiata dalam perbaikannya. Ini terlihat dari posisi ketiga atribut tersebut yang berada pada kuadran prioritas utama.

(4) Tri (3)

Tri benar-benar menunjukkan eksistensi dengan jargonnya "Always on". Hal ini terlihat pada gambar dimana atribut Masa aktif dan Masa tenggang perdana memiliki berada pada kuadran 2 dan memiliki skor kepuaasan tertinggi. Tetapi tri harus memperbaiki kekuatan sinyal dan luas area jaringan di kawasan lingkungan Jurusan Matematika. Ini terlihat dari tabel dan gambar dimana kekuatan sinyal berada pada kuadran yang dianggap penting namun 


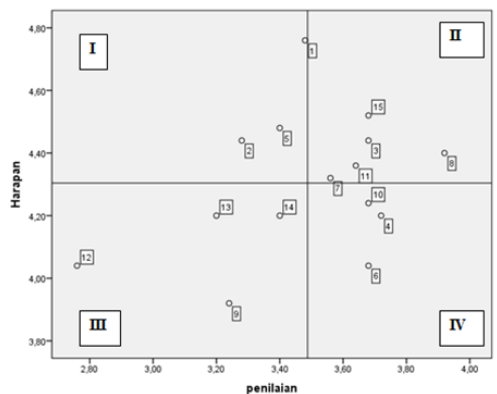

Gambar 4. Diagram Kartesius IPA Atribut-atribut Operator XL Axiata

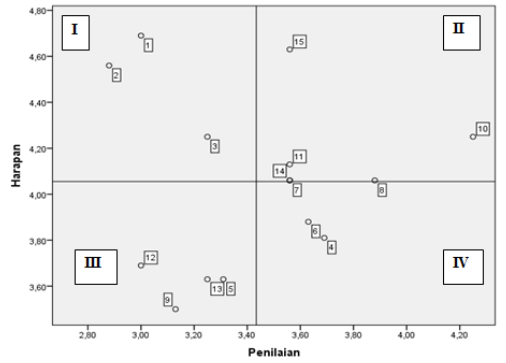

Gambar 5. Diagram Kartesius IPA Atribut-atribut Operator Tri(3)

pelaksanaannya belum sesuai harapan.

\subsection{Multidimensional Scaling}

Penentuan jumlah dimensi didasarkan pada nilai Stress untuk tiap dimensi. Untuk menentukan jumlah dimensi, Nilai Stress tersebut akan di plot pada Scree Plot berdasarkan jumlah dimensi nya.

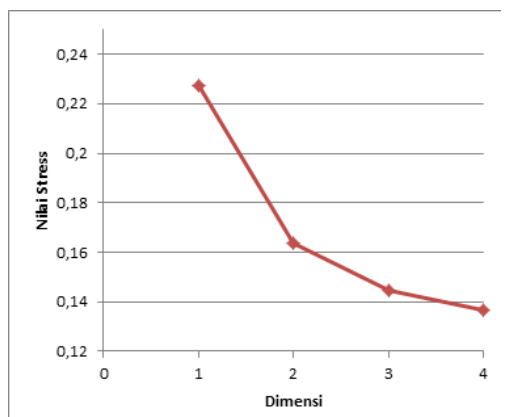

Gambar 6. Scree plot nilai stress dan dimensi

Dari Screen Plot diatas terlihat bahwa bentuk yang curam tepat pada angka 
dua. Kesimpulannya bahwa dengan menggunakan dua dimensi sudah cukup baik untuk menggambarkan kedekatan antar operator.

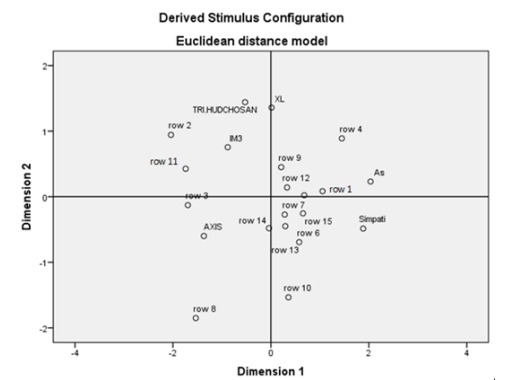

Gambar 7. Peta Posisi Operator Seluler di Jurusan Matematika

Dari gambar dapat diinterpretasikan bahwa berdasarkan preferensi mahasiswa Matematika UNAND, posisi As dan Simpati yang bernaung pada perusahaan Telkomsel berada pada posisi yang berdekatan. Artinya As dan Simpati memiliki kemiripan. Sementara As dan Simpati tidak memiliki kemiripan terhadap XL, Axis, IM3 dan Tri. Ini terlihat dari posisi produk Telkomsel ini yang jauh dari operator lain. Posisi IM3, Tri dan XL berada pada posisi yang berdekatan. IM3 dan Tri terletak pada dimensi 1 negatif dan dimensi 2 positif. Axis berdiri sendiri pada dimensi 1 negati dan dimensi 2 negatif. Artinya Axis tidak memiliki kemiripan terhadap operator GSM manapun. Pada spatial map terlihat bahwa row 1 (kekuatan sinyal) berada pada posisi yang dekat terhadap As dan Simpati artinya As dan Simpati unggul pada kekuatan sinyal. Ini bisa disebabkan oleh kualitas sinyal Telkomsel yang bagus.

\section{Ucapan Terima kasih}

Penulis mengucapkan terima kasih kepada Ibu Dr. Ferra Yanuar, Bapak Dr. Dodi Devianto, Bapak Yudiantri Asdi, M.Sc, Ibu Hazmira Yozza, M.Si dan Ibu Izzati Rahmi H.G., M. Si yang telah memberikan masukan dan saran sehingga makalah ini dapat diselesaikan dengan baik.

\section{Daftar Pustaka}

[1] Simamora, Bilson. 2004. Analisis Multivariat Pemasaran. Jakarta: Gramedia

[2] Anton, H dan P. Silaban. 1991. Aljabar Linier Elementer. Edisi Kedelapan Jilid 1. Jakarta: Erlangga

[3] Supranto, J. 2010. Analisis Multivariat: Arti dan Interpretasi. Jakarta: PT Rineka Cipta

[4] Borg, I. and Groenen, P. 2005. Modern Multidimensional Scaling: theory and applications (2nd ed.).New York: Springer-Verlag.

[5] Sugiyono. 2010. Statistika Untuk Penelitian. Bandung: Alfabeta, CV. 